\title{
Eosinophilic granulomatosis with polyangiitis (Churg-Strauss) syndrome and pulmonary thromboembolism: an overlooked concomitance
}

\author{
Vilma Takayasu ${ }^{a}$, Aloísio Felipe-Silvab
}

\begin{abstract}
Takayasu V, Felipe-Silva A. Eosinophilic granulomatosis with polyangiitis (Churg-Strauss) syndrome and pulmonary thromboembolism: an overlooked concomitance. Autopsy Case Rep [Internet]. 2013;3(2):11-19. http://dx.doi. org/10.4322/acr.2013.013
\end{abstract}

\section{ABSTRACT}

The Eosinophilic Granulomatosis with Polyangiitis (formerly Churg- Strauss Syndrome) (EGPA) is a systemic inflammatory disease characterized by the presence of rhinitis, asthma, peripheral eosinophilia, and vasculitis-the latter being characteristic of the late stage of the disease. After several years from the onset of the disease, small- and medium-sized vessel vasculitis ensues, undertaking various organs and systems. Upper and lower airways, skin, nervous system, gastrointestinal tract, heart, and kidneys are the most commonly involved organs. It is believed that tissue injury is the result of processes mediated by antineutrophil cytoplasmic antibody (ANCA), or toxic mediators released by eosinophils. Although it is classified as ANCA-associated vasculitis, these autoantibodies are present in only $40 \%$ of cases. The authors report the case of a patient with EGPA, who had a history of asthma, peripheral and central neuropathy, palpable purpura, gastrointestinal micro perforation, peripheral eosinophilia, and the presence of myeloperoxidase-antineutrophil cytoplasmic antibody. Inflammatory parameters improved after the initiation of treatment, but 1 month after hospital discharge the patient developed symptoms compatible with pulmonary embolism and died. Thrombophilia that occurs in EGPA is due to the interaction between the inflammatory response and eosinophilia with the clotting system resulting in a pro-thrombotic state. Although not yet well-determined, the authors call attention to the possibility of the impact of thromboembolic events on the prognosis of patients with EGPA. In addition to the adequate immunosuppressive treatment, prophylaxis and treatment for thrombosis should never be overlooked.

Keywords: Churg-Strauss Syndrome; Granulomatous Allergic Angiitis; Anti-Neutrophil Cytoplasmic Antibody-Associated Vasculitis; Asthma; Pulmonary Embolism; Autopsy.

\section{CASE REPORT}

A 66-year-old female patient sought medical care complaining of pain and numbness in the extremities for 1 month, which progressed to lower limb weakness preventing her from walking. Her family also referred some episodes of mental confusion. Initial laboratory workup included total blood cell count, which showed normal erythrocyte and platelet counts, but leukocytosis (white blood

\footnotetext{
${ }^{a}$ Department of Internal Medicine - Hospital Universitário - Universidade de São Paulo, São Paulo/SP - Brazil.

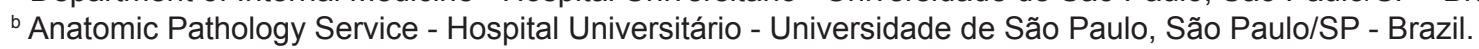

Copyright $\odot 2013$ Autopsy and Case Reports - This is an Open Access article distributed of terms of the Creative Commons Attribution NonCommercial License (http://creativecommons.org/licenses/by/3.0/) which permits unrestricted non-commercial use, distribution, and reproduction in any médium provided article is properly cited. 
cell count $=21.200 / \mathrm{mm}^{3}$ (reference value $[R V]$ : 5,000-10,000 leukocytes $/ \mathrm{mm}^{3}$ ) with marked eosinophilia ( $28 \%$ of eosinophils, RV: < $5 \%$ ). Serum determination of glucose, $\mathrm{TSH}$, free $\mathrm{T} 4$ and vitamin B12 were normal. Serology for HIV, HTLV I and HTLVII were negative. The chest $x$-ray was normal. The lumbar spine computed tomography (CT) showed degenerative changes. The electroneuromyography (EMG) showed subacute peripheral neuropathic process with motor and sensory impairment: severe distal axonal sensory impairment was predominant in upper and lower limbs; and severe proximal, middle, and distal axonal motor involvement in the left upper limb and was more pronounced in the lower limbs and right upper limb.

During ambulatory diagnostic investigation, the patient came to the emergency service complaining of diffuse abdominal pain with nausea and vomiting associated with skin lesions that appeared on her hands and feet. Physical examination showed an ill-looking patient, presenting mental confusion (coma Glasgow scale $=14$ ) with blood pressure of $167 / 100 \mathrm{mmHg}$, a pulse rate of 120 beats per minute (bpm), and room air oximetry of $99 \%$. Thoracic and abdominal examinations were unremarkable. Muscle strength was grade III/IV in the upper limbs (predominantly distal), and grade I in the lower limbs. The skin showed the presence of livedo reticularis over the trunk and palpable purpura on the tips of the toes and hands. Slight lower limb edema was present. Medical past history included hypertension, asthma, and allergic rhinitis regularly medicated. With these clinical features, the diagnosis of systemic vasculitis, most probably Eosinophilic Granulomatosis with Polyangiitis (formerly Churg- Strauss Syndrome) (EGPA) was considered, and the patient was hospitalized and prescribed a single dose of ivermectin before daily prednisone $60 \mathrm{mg}$, followed by ceftriaxone because of a suspected infection. The laboratory workup is shown in Table 1.

The anti-neutrophil cytoplasmic antibody ANCA (ELISA) was positive to myeloperoxidase (MPO) and negative to PR3. ANA was positive until titration of $1 / 160$ showing a nuclear centromeric pattern, and complement fractions $\mathrm{C} 3$ and $\mathrm{C} 4$ were normal. Serology for hepatitis $B$, hepatitis $C$, and syphilis were negative. Cerebrospinal fluid examination revealed a colorless sample with 1 leukocyte and 26 red blood cells, protein of 28.8 $\mathrm{mg} / \mathrm{dL}$ (RV: $30-40 \mathrm{mg} / \mathrm{dL}$ ), glucose of $61 \mathrm{mg} /$ $\mathrm{dL}$ (concomitantly with normal glycemia), and a negative Pandy reaction. The culture of blood samples, urine, and cerebrospinal fluid (CSF) were negative for bacterial growth. The urinalysis showed proteinuria; occult blood, leukocyturia; 173.000/ $\mathrm{mL}$, hematuria $278.000 / \mathrm{mL}$, but no cylindruria. The electrocardiogram (ECG) showed sinus tachycardia. Doppler echocardiography evidenced a thickened aortic valve with slight insufficiency. The paranasal sinuses computed tomography (CT) showed involvement of the left frontal, right sphenoid, and bilateral ethmoid sinuses. The chest CT showed tenuous mosaic attenuation of the lung parenchyma more pronounced in the bases; the presence of non-calcified nodules scattered bilaterally ranging in size between 5 and $10 \mathrm{~mm}$; and a hiatal hernia. The abdominal CT disclosed the presence of pneumoperitoneum of unknown origin.

The patient persisted with the complaint of epigastric abdominal pain but no signs of distension or peritoneal irritation were observed. The gastrointestinal transit was normal. The upper endoscopy revealed the presence of esophageal

Table 1 - Laboratory workup

\begin{tabular}{cccccc}
\hline Exam & Result & RV & Exam & Result & RV \\
\hline Hemoglobin & 10.1 & $12.3-15.3 \mathrm{~g} / \mathrm{dL}$ & Potassium & 4.7 & $3.5-5.0 \mathrm{mEq} / \mathrm{L}$ \\
Hematocrit & 30.7 & $36.0-45.0 \%$ & AST & 138 & $10-31 \mathrm{U} / \mathrm{L}$ \\
Leukocytes & 27.8 & $4.4-11.3 \times 10^{3} / \mathrm{mm}^{3}$ & ALT & 144 & $9-36 \mathrm{U} / \mathrm{L}$ \\
Eosinophil & $52 \%$ & $1-4 \%$ & CK & 1398 & $26-140 \mathrm{U} / \mathrm{L}$ \\
Platelet & 593 & $150-400 \times 10^{3} / \mathrm{mm}^{3}$ & LDH & 366 & $120-246 \mathrm{U} / \mathrm{L}$ \\
Creatinine & 0.6 & $0.4-1.3 \mathrm{mg} / \mathrm{dL}$ & TP & 6.0 & $6.0-8.0 \mathrm{~g} / \mathrm{dL}$ \\
Urea & 34 & $10-50 \mathrm{mg} / \mathrm{dL}$ & Albumin & 2.8 & $3.0-5.0 \mathrm{~g} / \mathrm{dL}$ \\
Sodium & 131 & $136-146 \mathrm{mEq} / \mathrm{L}$ & CRP & 191 & $<5.0 \mathrm{mg} / \mathrm{dL}$ \\
\hline
\end{tabular}

$\mathrm{ALT}=$ alanine aminotransferase; $\mathrm{AST}=$ aspartate aminotransferase; $\mathrm{CK}=$ creatine phosphokinase, $\mathrm{CRP}=\mathrm{C}$-reactive protein; LDH = lactic dehydrogenase; $\mathrm{RV}=$ reference value; $\mathrm{TP}=$ total protein. 
moniliasis and multiple acute superficial gastric ulcers, the biopsy of which revealed a chronic gastric ulcer edge in pyloric mucosa, Helicobacter pylori negative. These findings were interpreted as compatible with a tamponade gastric micro perforation. Because of steady clinical appearance, a proton-pump inhibitor was chosen instead of the surgical approach. Skin biopsy of the palmar injury showed sub epidermal necrosis with fibrin and erythrocytes. Neutrophilic vasculitis was depicted, showing vessel wall necrosis with red blood cell leakage permeated by eosinophils.

After the initiation of corticosteroid therapy, an improvement in mental status was observed as well as a decrease in the eosinophils count, creatine phosphokinase, and C-reactive protein determinations, and also a slight improvement in muscle strength. With the diagnosis of EGPA, the patient was referred to a specialized clinic for supplementary immunosuppressive therapy.

One month after the hospital discharge, she returned complaining of generalized pain and a burning sensation throughout the body. She denied fever, chest pain, breathlessness, or headache. On examination she was pale. Blood pressure was $130 / 82 \mathrm{mmHg}$, pulse rate of $92 \mathrm{bpm}$, room air oximetry of $92 \%$. Neurological examination revealed a distal symmetrical weakness (members distal muscle strength grade I and proximal grade III). The presence of scarring necrotic lesions on toes was noted. Four hours after admission, the patient presented sudden dyspnea, mental confusion, worsening of muscular weakness, pallor, and cold sweating, progressing to cardiac arrest and death. Recent laboratory workup showed a mild anemia (hemoglobin = $11.6 \mathrm{~g} / \mathrm{dL}, \mathrm{RV}: 13-15 \mathrm{~g} / \mathrm{dL}$ ). The remaining blood cell count, renal function, electrolytes, hepatic enzymes, CRP, CK, CK-MB and troponin I were all normal. The electrocardiogram showed a recent right bundle branch blockage. The acute clinical failure was interpreted as a pulmonary embolism. An autopsy was performed.

\section{AUTOPSY}

Resolving hemorrhagic skin lesions were seen on the hands and feet. At microscopic examination the lesions were in a chronic phase, with less fibrin deposition and more fibrosis and vascular occlusion (Figure 1).

Bilateral pulmonary thromboembolism was detected at gross examination (Figure 2). Right cardiac chambers were enlarged, which was consistent with acute cor pulmonale. A right pleural effusion was present and, at microscopic examination, the lungs showed alveolar hemorrhage, congestion, and edema. Small airways showed mild inflammation and basal membrane thickening, which was interpreted as treated asthma. Some subpleural small nodules had a dense fibrotic pigmented lesion which was consistent with silicoanthracosis (autopsy finding).

Active vasculitis with arteriolar wall necrosis, a palisade of histiocytes and inflammatory infiltrate with eosinophils and fibrin thrombi was present in skeletal muscle and at the periphery of nerves.
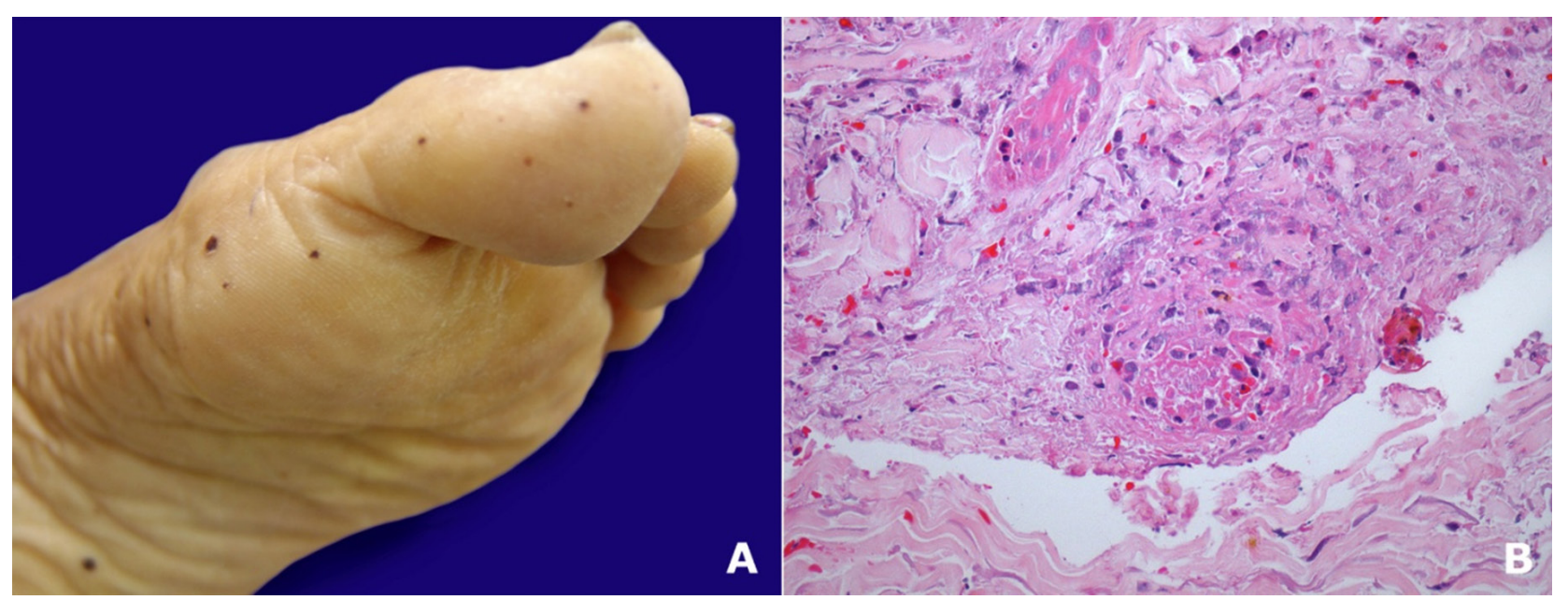

Figure 1 - A - Spotty resolving skin purpuric lesions; B - Photomicrography of the skin biopsy taken at the acute phase of the disease showing leukocytoclastic vasculitis (H\&E 200x). 
The gastrointestinal tract was particularly affected by active vasculitis. Inflammation of small arteries was detected in the wall of the esophagus and stomach, small bowel, colon, pancreas, and liver. The terminal jejunum and the proximal ileum showed active and healing ulcers, related to vasculitic lesions (Figure 3). A small infarct was detected in the liver. The gallbladder showed crateriform necrotic ulcers and mural vascular lesions in a chronic healing phase (Figure 4).

The kidneys were small and granular and at microscopy revealed moderate nephrosclerosis related to active and chronic eosinophilic and necrotic vasculitis with a palisade of histiocytes. Acute glomerulonephritis was not detected. Healing

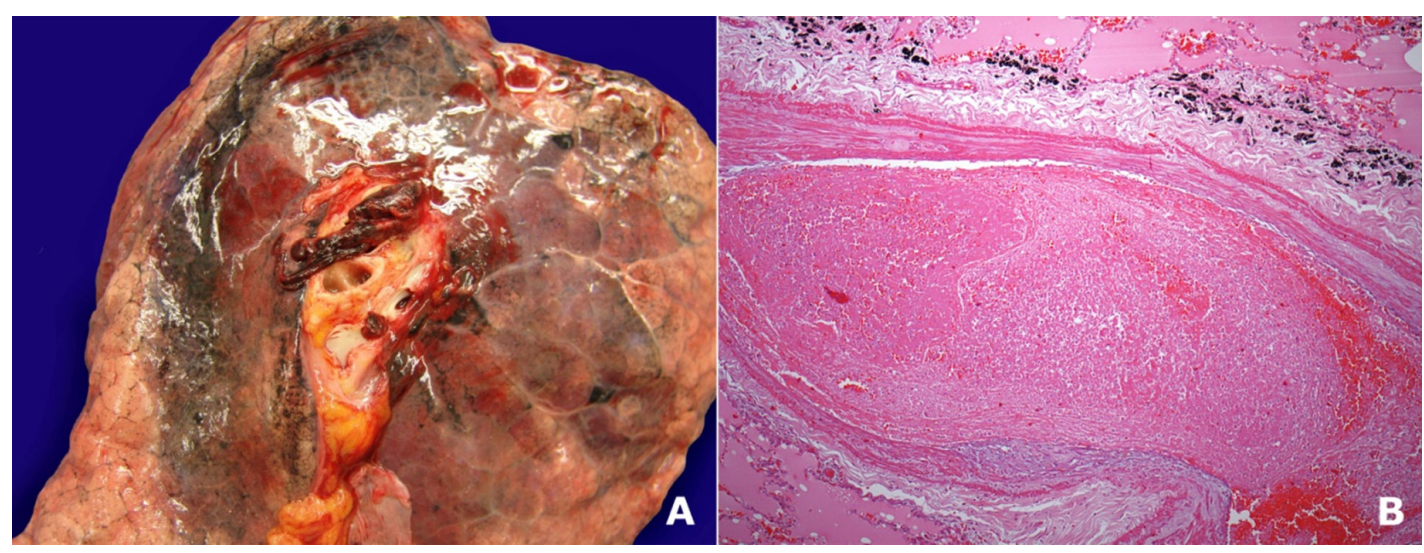

Figure 2 - A - Large thrombotic embolus occluding the left superior lobar pulmonary artery; B - Microscopic view of the thrombus (H\&E 12.5X).

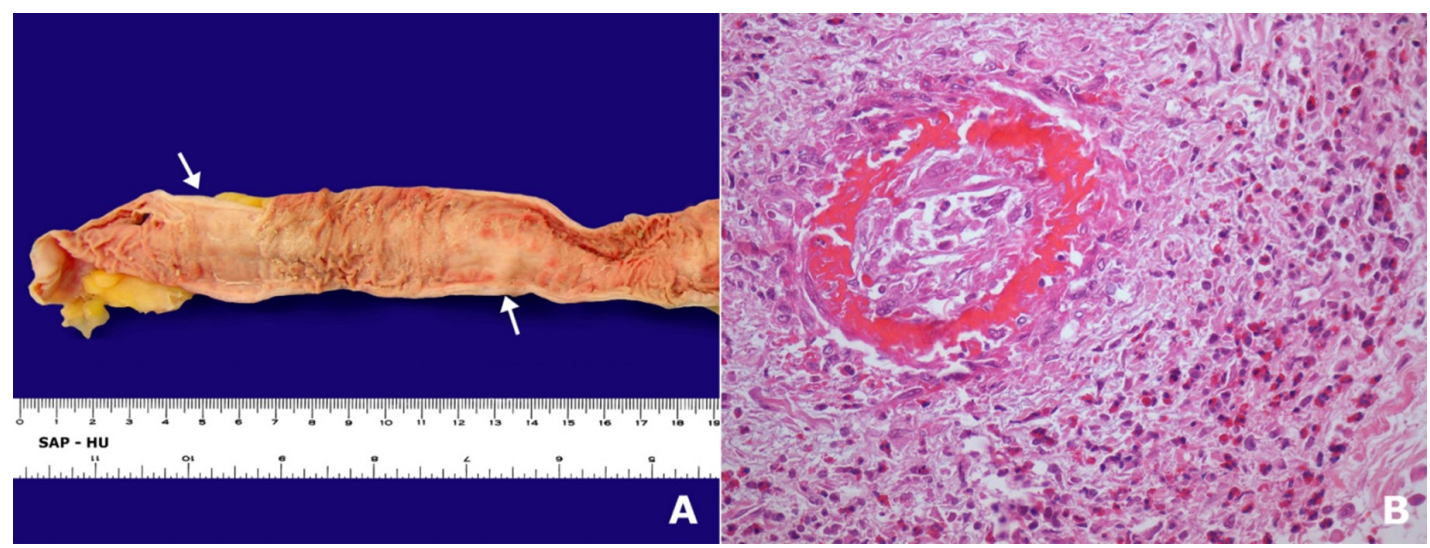

Figure 3 - A - Healed areas in the mucosa of the ileum (arrows); B - Small artery in the submucosa with fibrinoid necrosis, occlusion and a granulomatous reaction with palisade of histiocytes, neutrophils and many eosinophils (H\&E 400X).

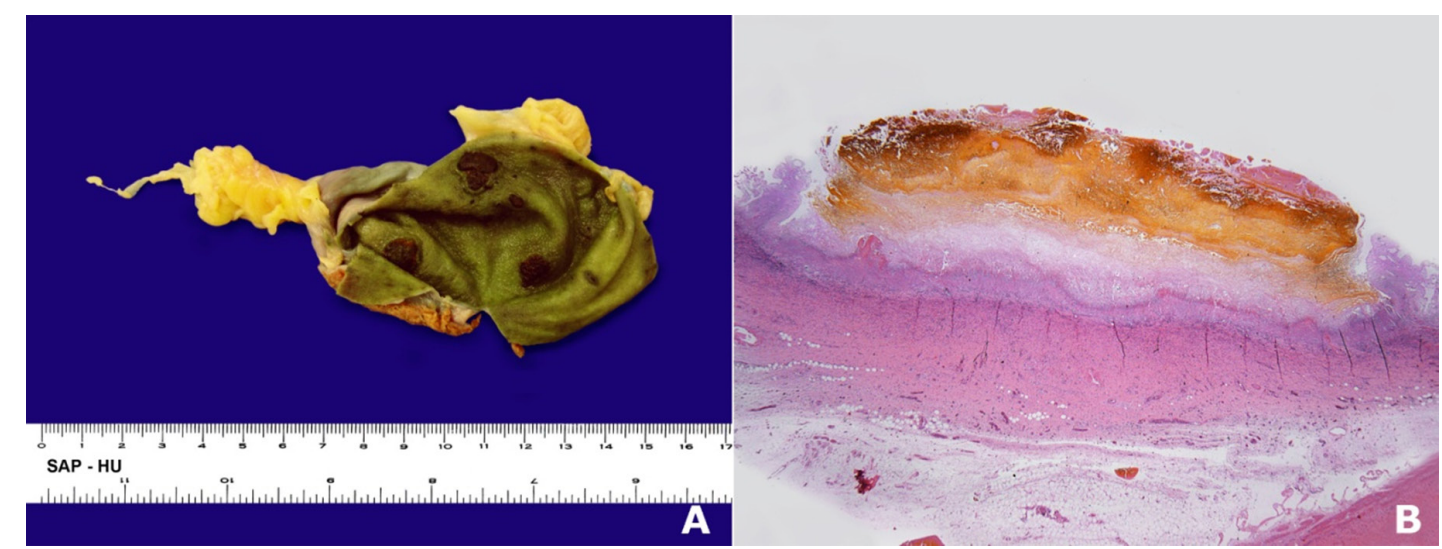

Figure 4 - A - Necrotic crateriform ulcers in the gallbladder; B - Microscopic view of a necrotic ulcer with undermining borders and impregnation with bile on the top (H\&E 12.5X). 
vasculitis, medium vessels thrombosis, and renal infarcts were present (Figure 5).

Microscopic vasculitis also affected the ovaries, adrenals, tongue, urinary bladder, and spleen. Vasculitis was not detected in the central nervous system (CNS) or in the heart.

\section{DISCUSSION}

The clinical features of this case report are compatible with the diagnosis of EGPA ${ }^{1}$, which is also called "allergic vasculitis" or "granulomatous angiitis." It is an uncommon systemic necrotizing vasculitis involving small- and medium-sized vessels of many organs, namely: the lungs, peripheral nerves, heart, and gastrointestinal tract. The estimated annual incidence ranges between 0.11 and 2.6 new cases per million, with a prevalence of 10.7-14 per million adults. The EGPA is sorted together with granulomatosis with angiitis (formerly called Wegener's granulomatosis) and microscopic polyangiitis as an ANCA-associated vasculitis. EGPA is the least frequent vasculitis among this group of diseases and represents about $10 \%$ of all ANCA-related vasculitis. ${ }^{2,3}$

The natural course of EGPA has three sequential phases, not always distinct: (1) the prodromal phase: usually present during the second and third decades of life, lasts months to years and is characterized by atopy, namely: allergic rhinitis and asthma; (2) the eosinophilic phase: characterized by peripheral eosinophilia ( $>10 \%$ of the differential count or over 1500 eosinophils $/ \mathrm{mm}^{3}$ ) and organic eosinophilic tissue infiltration, especially the lungs and gastrointestinal tract; and (3) vasculitic phase: comprehends the systemic involvement by severe vasculitis affecting small- and medium-sized vessels associated with vascular and extravascular granulomatosis compromising the lungs, peripheral nerves, heart, and gastrointestinal tract. If untreated, the mortality rate reaches $50 \%$ of patients in the first 3 months of disease..$^{2,4}$

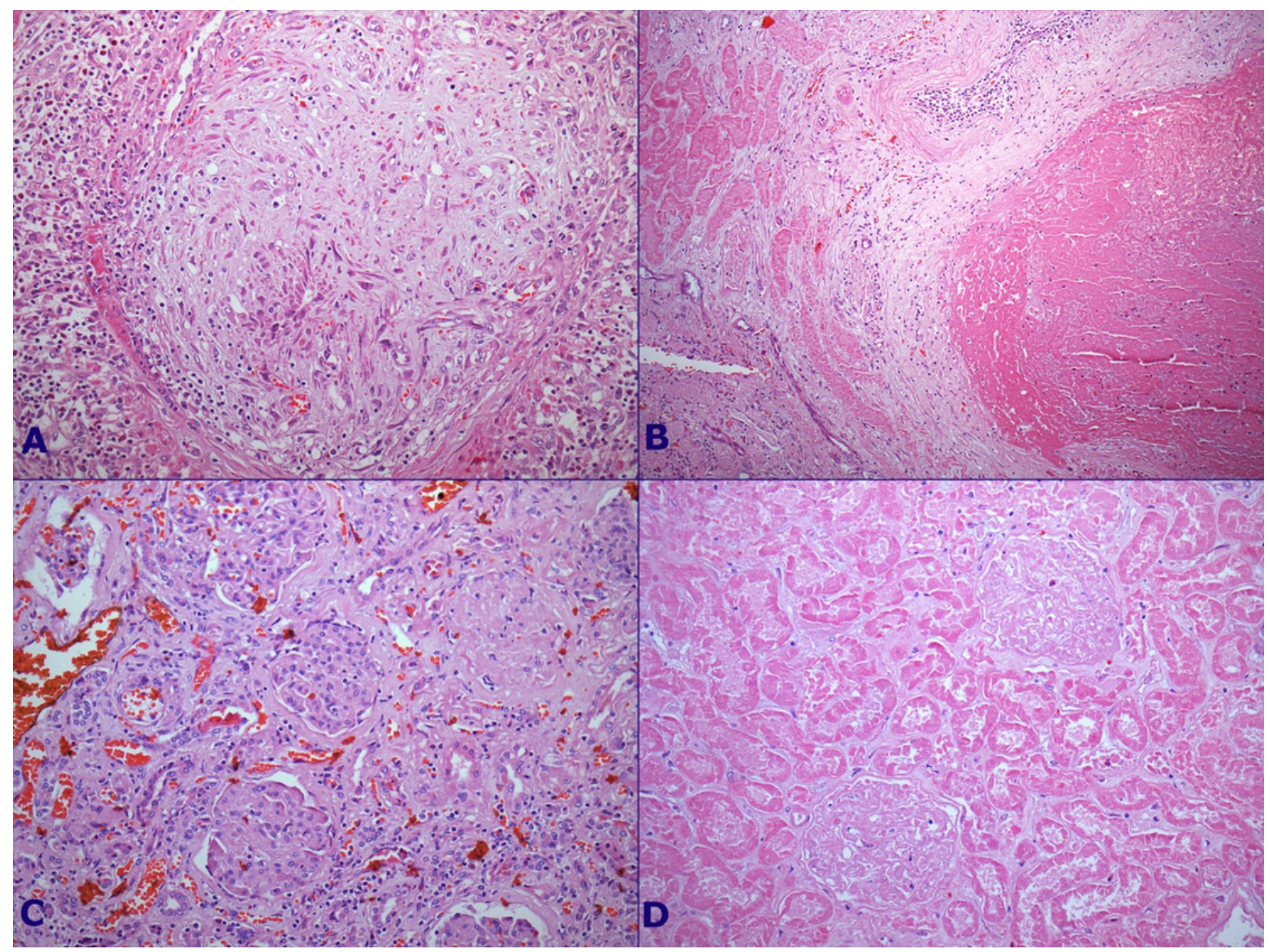

Figure 5 - A - Chronic vasculitis in a small kidney artery with luminal fibrosis (H\&E 400X); B - Local thrombosis in a medium-sized kidney artery (H\&E 100X); C - Glomerulosclerosis (H\&E 400X); D - Cortical renal infarction related to arterial thrombosis (H\&E 400X). 
The patient of this report had a 5-year history of asthma and rhinitis adequately controlled without the need for corticosteroids The presence of asthma is the main clinical feature in EGPA and is present in over $95 \%$ of cases. ${ }^{2}$ Asthma precedes vasculitis for an average of 3-9 years; it usually begins in adulthood and tends to be more severe and refractory to treatment. Many cases require prolonged use of systemic corticosteroids, which is why there may be a partial or total suppression of the usual EGPA clinical signs. When the dose of corticosteroids is reduced the EGPA becomes evident. When the vasculitic phase ensues, asthma exacerbations usually increase in severity. Rarely, the symptoms of asthma improve in the vasculitic phase. The symptoms related to the involvement of the upper airways are found in $47-93 \%$ of the cases and include nasal polyps, allergic rhinitis, and chronic or recurrent sinusitis. Necrotizing lesions of the nasopharynx and upper airway are more common in granulomatosis with polyangiitis and are rare in the EGPA. ${ }^{2,5}$

Other pulmonary findings include opacities with eosinophilia, pleural effusion (often eosinophilic), nodules that seldom cavitate, and alveolar hemorrhage. These findings are reported in $50-70 \%$ of cases. ${ }^{2,5}$

In the case of this report, the presence of sensory and motor peripheral neuropathy with pain and motor deficits was confirmed by electromyography. In addition, the patient developed mental confusion, which improved after the prescription of corticosteroids, suggesting CNS involvement. The peripheral nervous system involvement occurs in up to $75 \%$ of cases and is one of the most important manifestations of the vasculitic phase..$^{2,3}$ It usually starts as a mononeuritis multiplex (wrist or foot drop) and progress to symmetrical or asymmetrical polyneuropathy. Ischemic or hemorrhagic strokes and subarachnoid hemorrhage have also been reported but are rare and associated with poor prognosis and increased mortality. ${ }^{4}$

The skin lesions are very common in the vasculitic phase of EGPA. Palpable purpura, livedo reticularis, and subcutaneous nodules occur in up to $68 \%$ of cases. ${ }^{2,3}$ Nodules occur over the extensor surfaces of the lower and upper limbs-in the latter, it is particularly in the hands and elbows.

During the course of this case, abdominal complaints associated with tamponade gastrointestinal tract micro perforation appeared, but there was no need for surgical intervention. Probably a splanchnic vasculitis caused the gastric ischemia resulting in visceral wall necrosis and perforation. In the literature, there are several reports of single or multiple ulcers in the terminal ileum and colon, which progress to perforation requiring surgical treatment. ${ }^{6,7}$ The presence of ulceration on endoscopy is considered as a precursor lesion of perforation, and therefore particular attention should be given to the possibility of this severe complication. Corticosteroids increase the fibrotic changes within the vessel intima favoring vascular obstruction and consequently ischemia and further gastrointestinal perforation..$^{6,-8}$ Digestive symptoms, including abdominal pain, bowel obstruction, nausea, vomiting, diarrhea, and bleeding are common and can occur in up to one-third of cases. Other findings include eosinophilic ascites, pancreatitis, acalculous cholecystitis, and eosinophilic infiltrate of the liver. ${ }^{8}$

Cardiac involvement is one of the most severe manifestations of EGPA and is responsible for approximately half of the deaths. The myocardial damage may be due to three factors: (1) coronary artery vasculitis; (2) myocardial injury caused by toxic mediators released by activated eosinophils; and (3) myocardial sclerosis or granulomas. ${ }^{2,3}$ Recent studies show that cardiac involvement may be present in $44-62 \%$ of cases..$^{9,10}$ The manifestations are varied and include myocarditis, congestive heart failure, eosinophilic pericardial effusion, tamponade, valvular disease, and less often, coronary vasculitis. The occurrence of endomyocarditis may represent the most severe cardiac manifestation. ${ }^{9,10}$

Renal involvement occurs in approximately $25 \%$ of cases of EGPA. Half of these cases manifest isolated proteinuria or microscopic hematuria and the other half present acute renal failure or rapidly progressive renal failure. The most common histological finding in these cases is the ANCA-associated necrotizing crescentic glomerulonephritis. Less frequently, other renal histological findings include eosinophilic interstitial nephritis, mesangial glomerulonephritis, and focal sclerosis. ${ }^{11}$

Among the laboratory workup of this case, the marked eosinophilia with $52 \%$ of the leukocytes accounting for 14,456 eosinophils $/ \mathrm{mm}^{3}$ and the presence of ANCA were fundamental in supporting the diagnosis. These autoantibodies are found in $40-60 \%$ of patients with EGPA, and just as in the present case, the perinuclear pattern is the one 
associated with elevation of anti-myeloperoxidase ( $p$-ANCA or MPO-ANCA). ${ }^{9,10}$ The presence of ANCA at the time of diagnosis is more often associated with renal involvement, peripheral neuropathy, and vasculitic lesions demonstrated on biopsies, while the negativity of the ANCA is more often associated with heart disease and fever. ${ }^{12}$

Akimoto et al. ${ }^{13}$ observed a tendency for patients positive for $\mathrm{p}-\mathrm{ANCA}$ (anti-MPO antibody) to also be positive for other autoantibodies, such as anti-Sc1-70 antibody, anti-centromere antibody, antimicrosome antibody, anti-thyroglobulin antibody and rheumatoid factor. Anti-centromere antibody occurs in a marked frequency in progressive systemic sclerosis specially the CREST syndrome and may also be found in primary biliary cirrhosis, Sjoegren's syndrome, as well as in other autoimmune disorders, more rarely. The patient of this report exhibited a nuclear centromeric pattern at ANA testing, but did not show any clinical feature compatible with the above-cited diagnoses. We do not believe that the presence of this antibody, somehow, interfere with the established diagnosis of EGPA, but it is important to keep in mind that the presence of anticentromere may precede the CREST syndrome symptoms in years. ${ }^{14}$

The diagnostic criteria of the American College of Rheumatology (1990) ${ }^{15}$ for EGPA include the presence of asthma, peripheral eosinophilia (> $10 \%$ or $1,500 / \mathrm{mm}^{3}$ ), mononeuropathy (including mononeuritis multiplex) or polyneuropathy, transient pulmonary infiltration on chest radiography, involvement of paranasal sinuses, and the presence of eosinophils in extravascular biopsy containing a blood vessel. The presence of four or more diagnostic criteria determines a sensitivity of $85 \%$ and a specificity of $99.7 \%$ for the EGPA diagnosis.

After the diagnostic process, a five-factor score of poor prognosis should be considered to determine the severity of the disease. ${ }^{16}$ These factors encompass cardiac, gastrointestinal disease (bleeding, perforation, infarction, or pancreatitis), renal failure (creatinine $>1.58 \mathrm{mg} / \mathrm{dL}$ ), proteinuria (>1 g/day), and CNS involvement.

Recent studies showed an easy remission induction with corticosteroids if no poor-prognostic factor is present. ${ }^{2,3} \mathrm{In}$ these cases, the recommended initial dose is $1 \mathrm{mg} / \mathrm{kg}$ of prednisone $(0.5-1.5 \mathrm{mg} / \mathrm{kg})$ orally or equivalent for 6-12 weeks or until remission occurs with subsequent gradual dose tapering. When the disease is under control, a reduction of inflammatory activity and eosinophilia is observed. ${ }^{5}$ Intravenous corticosteroids pulse therapy (methylprednisolone $1 \mathrm{~g}$ IV for 3 days) is reserved for patients with more severe manifestations. In patients with a poor-prognostic factor, oral or intravenous cyclophosphamide pulses should be associated with the corticosteroids for 6-12 months. Once the remission is induced, methotrexate, azathioprine, or mycophenolate mofetil should replace cyclophosphamide in order to maintain remission, reduce side effects, and promote the possibility of further gradual reduction of the corticosteroids doses. The use of cyclophosphamide has also been recommended in patients with severe peripheral neuropathy with the goal of reducing or preventing sequelae..$^{17}$ In refractory cases, other therapeutic schemes may be used, such as plasmapheresis, intravenous immunoglobulin, antitumor-necrosis-factor (TNF [infliximab, etanercept, and adalimumab]), rituximab, and mepolizumab. ${ }^{2,3,18}$

According to the above recommendations, the patient of this report may have received cyclophosphamide and corticosteroids because of severe peripheral neuropathy and the presence of at least two poor prognostic factors, namely: gastrointestinal disease (perforation) and CNS involvement (mental confusion).

Currently, most clinical series show a 5-year survival rate greater than $70 \%$. Heart failure and/ or myocardial infarction, cerebral hemorrhage, renal failure, gastrointestinal bleeding, and status asthmaticus represent the most common causes of death. A large series of patients evaluated the survival according to the presence of poor-prognostic factors. After diagnosis, the 5-year mortality rate was $12 \%$ when none of these factors were present, $26 \%$ in the presence of one factor, and $46 \%$ when three or more risk factors were present. ${ }^{16}$

In the case presented here, the cause of death was pulmonary thromboembolism. In the last decade, several studies highlight the occurrence of a significantly increased risk of thromboembolic disease in ANCA-related vasculitis ${ }^{19-21}$ and with eosinophilic syndrome (hypereosinophilia and EGPA). ${ }^{22,23}$ In these cases, there is a release of several cytokines TNF- $\alpha$, interleukin-1 (IL-1) and interleukin-6 (IL-6), which activate the coagulation cascade favoring thrombosis. Thrombogenesis in EGPA is also related to eosinophilic tissue infiltration. The granules of eosinophils contain several proteins that are released when these cells are activated. Among these proteins are the 
tissue factor, eosinophilic cationic protein, and eosinophilic peroxidase, which have thrombotic effects. The mechanism by which eosinophils promote thrombosis includes platelet activation by tissue factor activation, blocking the anticoagulant activity of thrombomodulin by cationic proteins, and induction of tissue factor expression in endothelial cells by eosinophil peroxidase. In addition, eosinophils can synthesize and release the platelet activation factor (PAF), a potent mediator capable of inducing activation and platelet aggregation. Finally, eosinophils express CD40 ligand, involved in the initiation and progression of thrombosis by amplifying the inflammatory process. ${ }^{22,23}$

\section{A recent review found 80 cases of thrombosis} associated with EGPA. ${ }^{23}$ Venous thrombosis occurred in $57 \%$ of cases, arterial thrombosis in $39 \%$, and mixed thrombosis (arterial and venous) occurred in $4 \%$. Frequently, these events are represented by deep vein thrombosis $(34 \%)$ and occlusion of retinal vessels (23\%). Pulmonary embolism occurred in $8 \%$ of cases.

\section{CONCLUSION}

Since patients with EGPA are at high risk of venous or arterial thrombosis and such events are more frequent during active disease, we emphasize the requirement of prophylaxis and/or treatment of thromboembolic complications in addition to immunosuppressive treatment.

\section{REFERENCES}

1. Jennette JC, Falk RJ, Bacon PA, 2012 Revised International Chapel Hill Consensus Conference Nomenclature of Vasculitides. Arthritis Rheum. 2013;65:1-11. 10.1002/art.37715 http://dx.doi.org/10.1002/art.37715

2. Baldini C, Talarico R, Della Rossa A, Bombardieri S. Clinical manifestations and treatment of Churg-Strauss syndrome. Rheum Dis Clin N Am. 2010;36:527-43. PMid:20688248. http://dx.doi.org/10.1016/j.rdc.2010.05.003

3. Abril A. Churg-Strauss Syndrome: an update. Curr Rheumatol Rep. 2011;13:489-95. PMid:21863326. http://dx.doi. org/10.1007/s11926-011-0205-7

4. Guillevin L, Cohen P, Gayraud M, Lhote F, Jarrousse $B$, Casassus P. Churg-Strauss syndrome. Clinical study and longterm follow-up of 96 patients. Medicine (Baltimore). 1999;78:26-37. http://dx.doi. org/10.1097/00005792-199901000-00003
5. Sinico RA, Botteron P. Churg-Strauss angiitis. Best Pract Res Clin Rheumatol. 2009;23:355-66. PMid:19508943. http://dx.doi.org/10.1016/j.berh.2009.02.004

6. Venditti D, Valerio B, lelpo B, Buonomo O, Petrella G. Bowel perforations in a patient affected by Churg-Strauss syndrome under high-dose steroid treatment: will alternative drugs reduce risk of surgery? Rheumatol Int. 2011;31:1239-41. PMid:20012623. http://dx.doi.org/10.1007/s00296-009-1289-5

7. Nakamura Y, Sakurai Y, Matsubara T, et al. Multiple perforated ulcers of the small intestine associated with allergic granulomatous angiitis: report of a case. Surg Today. 2002;32:541-6. PMid:12107783. http://dx.doi. org/10.1007/s005950200094

8. Ahn E, Luk A, Chetty R, Butany J. Vasculitides of the gastrointestinal tract. Semin Diagn Pathol. 2009;26:77-88. http://dx.doi.org/10.1053/j.semdp.2009.06.001

9. Neumann T, Manger B, Schmid M, et al. Cardiac involvement in Churg-Strauss syndrome: impact of endomyocarditis. Medicine. 2009;88:236-43. PMid:19593229. http://dx.doi. org/10.1097/MD.0b013e3181af35a5

10. Dennert RM, van Paassen P, Schalla S, et al. Cardiac involvement in Churg-Strauss Syndrome. Arthritis Rheum. 2010;62:627-34. PMid:20112390.

11. Sinico RA, Di Toma $L$, Maggiore $U$, et al. Renal involvement in Churg-Strauss syndrome. Am J Kidney Dis. 2006;47:770. PMid:16632015. http://dx.doi.org/10.1053/j.ajkd.2006.01.026

12. Sable-Fourtassou R, Cohen P, Mahr A, French Vasculitis Study Group. Antineutrophil cytoplasmic antibodies and the Churg-Strauss syndrome. Ann Intern Med. 2005;143:632-8. http://dx.doi.org/10.7326/0003-4819-143-9-200511010-00006

13. Akimoto S, Ishikawa O, Tamura T, Miyachi Y. Antineutrophil cytoplasmic autoantibodies in patients with systemic sclerosis. Br J Dermatol. 1996;134:407-10. http://dx.doi. org/10.1111/j.1365-2133.1996.tb16222.x

14. Dellavance A, Gabriel Júnior A, Nuccitelli B, et al. 3o Consenso Brasileiro para pesquisa de autoanticorpos em Celulas HEp-2 (FAN): recomendações para a padronização do ensaio de pesquisa de autoanticorpos em células HEp2 , controle de qualidade e associações clínicas. Rev Bras Reumatol. 2009;49:89-109. Portuguese. http://dx.doi. org/10.1590/S0482-50042009000200002

15. Masi AT, Hunder GG, Lie JT, et al. The American College of Rheumatology 1990 criteria for the classification of ChurgStrauss syndrome (allergic granulomatosis and angiitis). Arthritis Rheum. 1990,33:1094-100. PMid:2202307. http:// dx.doi.org/10.1002/art.1780330806

16. Guillevin L, Lhote F, Gayraud M, et al. Prognostic factors in polyarteritis nodosa and Churg-Strauss syndrome. A prospective study in 342 patients. Medicine (Baltimore). 1996;75:17-28. http://dx.doi. org/10.1097/00005792-199601000-00003

17. Hoi AY, Morand EF. Churg-Strauss syndrome: the use of cyclophosphamide in mononeuritis. 
Rheumatology. 2003;42:390-1. http://dx.doi.org/10.1093/ rheumatology/keg067

18. Vaglio A, Buzio C, Zwerina J. Eosinophilic granulomatosis with polyangiitis (Churg-Strauss): state of the art. Allergy. 2013;68:261-73. PMid:23330816. http://dx.doi. org/10.1111/all.12088

19. Allenbach $Y$. High frequency of venous thromboembolic events in Churg-Strauss syndrome, Wegener's granulomatosis and microscopic polyangiitis but not polyarteritis nodosa: a systematic retrospective study on 1130 patients. Ann Rheum Dis. 2009;68:564-7. PMid:19015208. http://dx.doi. org/10.1136/ard.2008.099051

20. Springera J, Villa-Forteb A. Thrombosis in vasculitis. Curr Opin Rheumatol. 2013;25:19-25. PMid:23143223. http:// dx.doi.org/10.1097/BOR.0b013e32835ad3ca
21. Stassen PM, Derks RPH, Kallenberg CGM, Stegeman CA. Venous thromboembolism in ANCA-associated vasculitis: incidence and risk factors. Rheumatology. 2008;47:530-4. PMid:18356178. http://dx.doi.org/10.1093/rheumatology/ ken035

22. Ames PRJ, Margaglione M, Mackie S, Delgado Alves J. Eosinophilia and thrombophilia in Churg-Strauss syndrome: a clinical and pathogenetic overview. Clin Appl Thromb Hemost. 2010;16:628-36. PMid:19833618. http://dx.doi. org/10.1177/1076029609348647

23. Maino A, Rossio R, Cugno M, Marzano AV, Tedeschi A. Hypereosinophilic syndrome, Cshurg-Strauss syndrome and parasitic diseases: possible links between eosinophilia and thrombosis. Curr Vasc Pharmacol. 2012;10:670-5. http:// dx.doi.org/10.2174/157016112801784594

\section{Conflict of interest: None}

Submitted on: $15^{\text {th }}$ January 2013

Accepted on: $6^{\text {th }}$ June 2013

Correspondence: Serviço de Anatomia Patológica

Av. Prof. Lineu Prestes, 2565 - Cidade Universitária - São Paulo/SP - Brazil

CEP: 05508-000 - Phone: +55 (11) 3091-9384

E-mail: aloisiosilva@hu.usp.br 